\title{
Large and Stable Transmembrane Pores from Guanosine-Bile Acid Conjugates
}

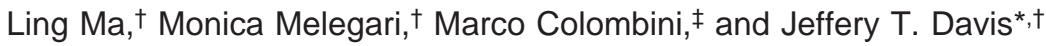 \\ Department of Chemistry and Biochemistry and Department of Biology, University of Maryland, \\ College Park, Maryland 20742
}

Received December 18, 2007; E-mail: jdavis@umd.edu

A variety of natural and synthetic compounds are known to selfassemble to give transmembrane ion channels. ${ }^{1}$ Hydrogen-bonded macrocycles that can $\pi$-stack are a new type of channel motif. ${ }^{2}$ Thus, folate quartets stack to give ion channels in lipid bilayers. ${ }^{3}$ This folate assembly had a single-channel conductance of 10-20 picosiemens (pS), values consistent with the quartet's $3 \AA$ diameter. We found that a noncovalent assembly of 16 guanosine monomers could be cross-linked to give a "unimolecular" G-quadruplex that can transport $\mathrm{Na}^{+}$across lipid membranes. ${ }^{4}$

We now report that the ditopic guanosine-lithocholate $\mathbf{1}$ forms discrete channels in phospholipid membranes (Figure 1). These pores are large (nS conductance) and stable, with "open" times of seconds, distinguishing them from most synthetic channels, which typically conduct in the $\mathrm{pS}$ range with millisecond lifetimes. ${ }^{1,5}$

Lehn and Barboiu have independently shown that ditopic monomers with guanine end groups form supramolecular polymers in cation-templated processes. ${ }^{6}$ Possible supramolecular structures built from these ion-templated $\mathrm{G}_{4}$-quartets are depicted in Figure 2. In addition to the $\mathrm{G}_{4}$-quartet channel, such structures might well stack to form pores for transmembrane transport. Of relevance was Barboiu's demonstration that $\mathrm{Na}^{+}$and $\mathrm{K}^{+}$could be transported across films made from $\mathrm{G}_{4}$-quartet polymers. ${ }^{6 \mathrm{~b}}$

The nucleoside-sterol conjugate $\mathbf{1}$ has two guanosine groups connected by a bis-lithocholate linker. This spacer was inspired by Kobuke's studies that showed that bis-cholic acid derivatives formed cation-selective channels with $\mathrm{pS}$ conductance. ${ }^{7,8} \mathrm{We}$ envisioned that membrane insertion of $\mathbf{1}$, followed by formation of $\mathrm{G}_{4}$-quartets, might well provide functional pores (Figure 2).

Compound 1 was made by coupling $2^{\prime}, 3^{\prime}$-tBDMSi-5'-amino G, ${ }^{9}$ with a bis-lithocholic acid. Compound 2, with -NMe amide end groups, was a control. The ${ }^{1} \mathrm{H}$ NMR spectrum of $\mathbf{1}$ gave sharp peaks in DMSO- $d_{6}$, a polar solvent that inhibits self-assembly mediated by hydrogen bonding. In contrast, the NMR spectrum of $\mathbf{1}$ in $\mathrm{CDCl}_{3}$ gave much broader signals, consistent with self-association in this "poor" solvent.

We used CD spectroscopy to gain evidence that $\mathbf{1}$ forms stacked $\mathrm{G}_{4}$-quartets in a nonpolar solvent. ${ }^{10}$ Figure 3 shows CD spectra for samples of $\mathbf{1}$ in $\mathrm{CHCl}_{3}$. The $\mathrm{CD}$ spectrum of $\mathbf{1}$ (blue) was taken after isolation from a silica gel. This sample showed a weak Cotton band in the 200-280 nm region, suggesting some stacked $\mathrm{G}_{4^{-}}$ quartets. ${ }^{10}$ We added [2.2.2]-cryptand to ensure that any adventitious cations bound by 1 were sequestered. Indeed, the resulting spectrum (green trace) was inactive. We next stirred the mixture of $\mathbf{1}$ and [2.2.2]-cryptand in the presence of excess $\mathrm{K}^{+}$2,6-dinitrophenolate (DNP). The CD spectrum of ditopic 1 was much different after extraction of $\mathrm{K}^{+} \mathrm{DNP}^{-}$(red trace). This sample showed a $\mathrm{CD}$ signature diagnostic for stacked G-quartets, with a positive band at $\lambda=266 \mathrm{~nm}$ and a negative peak at $\lambda=240 \mathrm{~nm} .{ }^{10}$ The complex

\footnotetext{
Department of Chemistry and Biochemistry.

$\$$ Department of Biology.
}

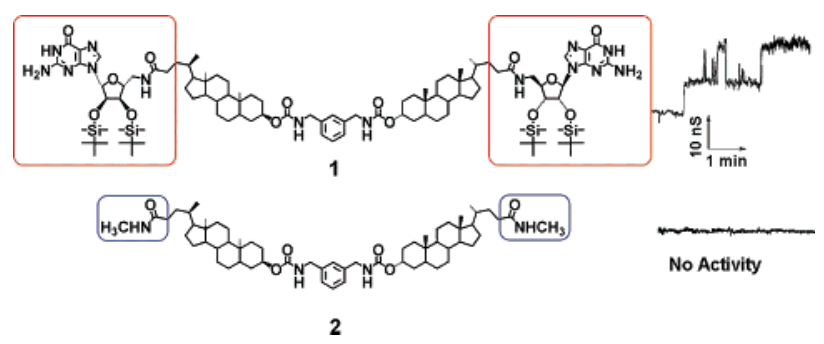

Figure 1. Ditopic G-sterol 1 and control bis-lithocholamide 2. Typical traces of conductance vs time, after addition of $\mathbf{1}$ or $\mathbf{2}$, are depicted. The guanosine end-groups are needed to form a transmembrane channel.
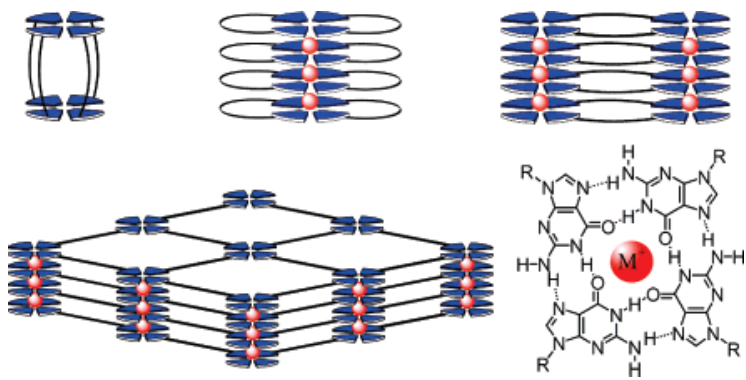

Figure 2. Possible $\mathrm{G}_{4}$-quartet stacks formed by bis-G-lithocholate $\mathbf{1}$ in a cation templated process.

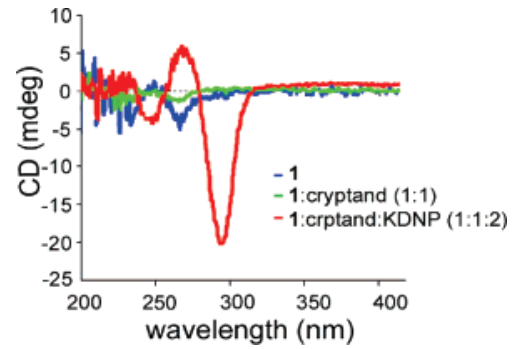

Figure 3. $\mathrm{CD}$ spectra of guanosine-sterol $1(0.43 \mathrm{mM})$ in $\mathrm{CHCl}_{3}$ at room temperature (blue line), after addition of 1 equiv of [2,2,2]-cryptand (green line), and after solid-liquid extraction of $\mathrm{K}^{+} \mathrm{DNP}^{-}$(red line). All spectra were obtained in $\mathrm{CHCl}_{3}$.

formed by $\mathbf{1}$ and $\mathrm{K}^{+}$also showed a strong Cotton band at $\lambda=295$ $\mathrm{nm}$, a signal that has been previously observed for G-quadruplexes formed from both nucleosides and DNA strands. ${ }^{11,12}$ The control compound, NMe amide 2 , showed no CD activity under identical conditions. These data indicate that the $\mathrm{K}^{+}$ion can template formation of stacked $\mathrm{G}_{4}$-quartets by $\mathbf{1}$ in a nonpolar environment.

We next used voltage-clamp experiments to show that $\mathbf{1}$ forms single channels in planar membranes; some of these channels had remarkably long lifetimes and large conductance values for pores made from a synthetic compound. ${ }^{13}$ Figure 4 shows representative records of conductance, as mediated by $\mathbf{1}$, in a planar bilayer at an applied voltage of $-10 \mathrm{mV}$ in $1 \mathrm{M} \mathrm{KCl}$ (trans)/KCl (cis) solution 


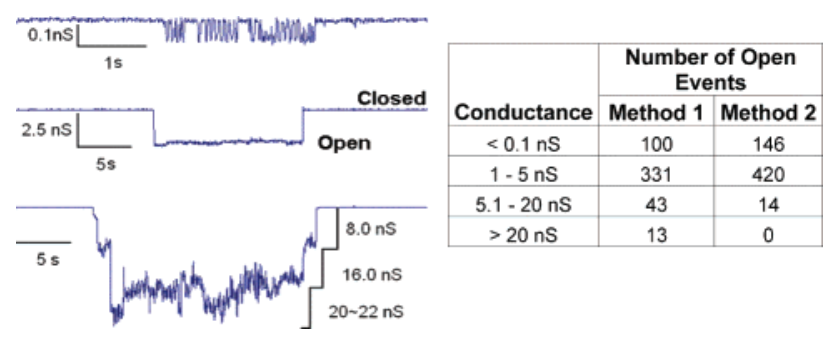

Figure 4. Representative traces from voltage-clamp experiments indicating distinct conductance values recorded in the presence of $\mathbf{1}$ at $-10 \mathrm{mV}$ in 1 $\mathrm{M} \mathrm{KCl}$. The number of open events are counted from a total of six experiments. Three of the experiments were conducted by adding compound $1(3.1 \mathrm{mM})$ to the cis side of the chamber after the planar bilayer membrane was formed (Method 1 in Supporting Information). The other three experiments were done using membranes that contained compound $\mathbf{1}(0.26$ $\mathrm{mM}$ ) premixed with the phospholipids used to form membrane (Method 2 in Supporting Information).

(pH 7.0). After either application of $\mathbf{1}$ to the cis side of the planar bilayer (Method 1) or after premixing compound $\mathbf{1}$ with the lipid mixture (Method 2), conductance states of different magnitudes appeared and disappeared over a $2-3 \mathrm{~h}$ period. This pattern of "open" and "closed" conductance is consistent with dynamic formation and disintegration of self-assembled channels formed by 1.

The magnitude and lifetimes of ion conductance supported by 1 varied during a single experiment (Figure 4). Channels with conductance values of $0.1-1.0 \mathrm{nS}$ typically had the shortest open lifetimes $(10-80 \mathrm{~ms})$. These smaller channels always appeared during initial events in any experiment. Larger channels with conductance levels of 1-5 $\mathrm{nS}$ had much longer open lifetimes, typically lasting longer than $10 \mathrm{~s}$. Formation and disassembly of pores with $1-5 \mathrm{nS}$ conductance were also the most frequent events observed during any experiment. We occasionally observed long periods of larger conductance $(>20 \mathrm{nS})$ in the three experiments that used the Method 1 protocol for introduction of compound 1. Analysis of data from these six experiments showed similar numbers of increments and decrements at discrete conductance values, consistent with the opening and closing of channels of the same size. The most frequent conductance increments and decrements were on the order of 1-5 nS. Significantly, addition of control 2 to planar bilayer membranes never resulted in measurable conductance. Apparently, the guanosine end groups in compound $\mathbf{1}$ are essential for pore formation and transmembrane ion transport.

Reversal potentials, recorded in the presence of a 10 -fold $\mathrm{KCl}$ gradient, were measured to determine the ion selectivity of the channels. The reversal potential, $E_{\mathrm{rev}}$, was essentially constant for the $1-5 \mathrm{nS}$ channels, suggesting no significant enlargement or contracture of these pores during an experiment. The ion selectivity of the 1-5 nS channels, calculated from the Goldman-HodgkinKatz equation, ${ }^{14}$ revealed a cation selective pore $\left(P_{\mathrm{K}}{ }^{+} / P_{\mathrm{Cl}}{ }^{-}=6.38\right.$ $\pm 0.30)$. The Hille equation was used to estimate a channel diameter of $\sim 2.6-2.7 \AA$ for the smaller channels $(0.1 \mathrm{nS}$ at $1 \mathrm{M} \mathrm{KCl}), 5 \mathrm{c}, 13,14$ a value that is quite close to the diameter of the $\mathrm{G}_{4}$-quartet's central cavity. The pores that conduct in the $\mathrm{nS}$ range must, however, be much larger than a G-quartet. For instance, the Hille diameter for a single channel of $2.5 \mathrm{nS}$ was estimated to be about $12 \AA$. Such a single channel is significantly larger than the diameter of $\mathrm{a}_{4^{-}}$ quartet, suggesting that ion transport likely proceeds through larger pore(s) that form upon self-assembly of guanosine-lithocholamide
1 within the phospholipid bilayer. We envision that the bislithocholate linker in $\mathbf{1}$ provides the walls for the transmembrane pore and a cation-filled G-quadruplex, formed upon hydrogen-bond self-assembly, serves as a structural pillar that anchors the assembly within the membrane.

In summary, ditopic guanosine-sterol 1 forms large and stable channels. The smaller conductance values near $0.1 \mathrm{pS}$ may arise as ions are moved through the central channel of a G-quadruplex. ${ }^{3}$ However, pores that conduct on the $1-20 \mathrm{nS}$ scale must necessarily have diameters that are significantly larger than that provided by a $\mathrm{G}_{4}$-quartet. It is tempting to suggest that assemblies like those depicted in Figure 2, structures previously proposed to explain formation of $\mathrm{G}_{4}$-quartet polymers,${ }^{6}$ are responsible for the function of 1. Regardless of the actual membrane-active structures, the demonstration that $\mathbf{1}$ forms large and stable transmembrane channels suggests that this nucleoside-sterol may well be able to allow larger biomolecules to move in and out of liposomes and/or cells. We are currently pursuing such studies.

Acknowledgment. J.D. thanks the Department of Energy for support. J.D. and M.C. thank the Maryland Department of Economic and Business Development for support from the Maryland NanoBiotechnology Initiative.

Supporting Information Available: Experimental details and spectra. This material is available at http://pubs.acs.org

\section{References}

(1) (a) Fyles, T. M. Chem. Soc. Rev. 2007, 36, 335-347. (b) Sakai, N.; Mareda, J.; Matile, S. Mol. BioSyst. 2007, 3, 658-666.

(2) (a) Bhosale, S.; Sisson, A. L.; Sakai, N.; Matile, S. Org. Biomol. Chem 2006, 4, 3031-3039. (b) Davis, J. T.; Spada, G. P. Chem. Soc. Rev. 2007 36, 296-313. (c) Davis, J. T. Angew. Chem., Int. Ed. 2004, 43, 668698.

(3) Sakai, N.; Kamikawa, Y.; Nishii, M.; Matsuoka, T.; Kato, T.; Matile, S. J. Am. Chem. Soc. 2006, 128, 2218-2219.

(4) Kaucher, M. S.; Harrell, W. A., Jr.; Davis, J. T. J. Am. Chem. Soc. 2006, 128, 38-39.

(5) For exceptional synthetic channels that do show $\mathrm{nS}$ conductance, see: (a) Baumeister, B.; Sakai, N.; Matile, S. Angew. Chem., Int. Ed. 2000, 39 1955-1958. (b) Schlesinger, P. H.; Ferdani, R.; Liu, J.; Pajewska, J.; Pajewki, R.; Saito, M.; Shabany, H.; Gokel, G. W. J. Am. Chem. Soc. 2002, 124, 1848-1849. (c) Fyles, T. C.; Tong, C. C. New J. Chem. 2007 $31,655-661$.

(6) (a) Ghoussob, A.; Lehn, J.-M. Chem. Commun. 2005, 5763-5765. (b) Arnel-Herault, C.; Pasc, A.; Michau., M.; Cot, D.; Petit, E.; Barboiu, M. Angew. Chem., Int. Ed. 2007, 46, 8409-8413.

(7) (a) Yoshii, M.; Yamamura, M.; Satake, A.; Kobuke, Y. Org. Biomol. Chem. 2004, 2, 2619-2623. (b) Kobuke, Y.; Nagatani, T., J. Org. Chem. 2001, 66, 5094-5101. (c) Goto, C.; Yamamura, M.; Satake, Y.; Kobuke, Y. J. Am. Chem. Soc. 2002, 123, 12152-12159.

(8) Other cholates that are membrane-active ionophores: (a) Bandyopadhyay, P.; Janout, V.; Zhang, L.; Sawlo, J. A.; Regen, S. L. J. Am. Chem. Soc. 2000, 122, 12888-12889. (b) Koulov, A. V.; Lambert, T. N.; Shukla, R.; Jain, M.; Boon, J. M.; Smith, B. D.; Li, H.; Sheppard, D. N.; Joss, J.-B.; Clare, J. P.; Davis, A. P. Angew. Chem., Int. Ed. 2003, 42, 49314933. (c) De Riccardis, F.; Di Filippo, M.; Garrisi, D.; Izzo, I.; Mancin, F.; Pasquato, L.; Scrimin, P.; Tecilla, P. Chem. Commun. 2002, 30663067.

(9) Kotch, F. W.; Sidorov, V.; Lam, Y. F.; Kayser, K. J.; Li, H.; Kaucher, M. S.; Davis, J. T. J. Am. Chem. Soc. 2003, 125, 15140-15150.

(10) For a review on the CD spectroscopy of G-quadruplexes: Gottarelli, G. Masiero, S.; Spada, G. P. Enantiomer 1999, 3, 429-438.

(11) Gottarelli, G., Masiero, S., Spada, G. P. Chem. Commun. 1995, 25552557.

(12) (a) Lu, M., Guo, Q., Kallenbach, N. R. Biochemistry 1993, 32, 598-601. (b) Porumb, H.; Monnot, M.; Fermandjian, S. Electrophoresis 2002, 23, 1013-1020.

(13) (a) Siskind, L. J.; Colombini, M., J. Biol. Chem. 2000, 275, 38640-38644. (b) Siskind, L. J.; Davoody, A.; Lewin, N.; Marshall, S.; Colombini, M., Biophys. J. 2003, 85, 1560-1575.

(14) Hille, B. Ionic Channels of Excitable Membranes, 3rd ed.; Sinauer Associates: Sunderland, MA, 2001.

JA7110702 